\title{
Optimization of phosphate removal from aqueous solution using activated carbon supported zero-valent iron nanoparticles: application of RSM approach
}

\author{
Arun K. Singh ${ }^{1,2} \cdot$ Kunwar P. Singh $^{1}$
}

Received: 9 May 2018 / Accepted: 7 November 2018 / Published online: 16 November 2018

(C) The Author(s) 2018

\begin{abstract}
In this study, activated carbon (AC) prepared from cork powder was used in synthesis of AC stabilized nano-zero-valent iron (AC/NZVI) composite and evaluated phosphate $\left(\mathrm{PO}_{4}{ }^{3-}\right)$ removal efficiency from aqueous solution. The as-obtained $\mathrm{AC} /$ NZVI was characterized by scanning electron microscopy (SEM), Brunauer-Emmett-Teller (BET) and X-ray diffraction (XRD) analysis. Response surface methodology based on a three-level, three-factor, Box-Behnken design (B.B.D.) has been employed for determination of optimal combination of three significant process factors or variables such as temperature, solution $\mathrm{pH}$ and $\mathrm{AC} / \mathrm{NZVI}$ dose, for maximum removal of $\mathrm{PO}_{4}{ }^{3-}$ from aqueous solution. Based on B.B.D. experimental design, a limited number of experiments were performed in a cost-effective manner at initial $\mathrm{PO}_{4}{ }^{3-}$ concentration of $211 \mathrm{mg} \mathrm{L}^{-1}$ as a fixed input parameter. A statistically validated quadratic model was developed to predict the responses in the form $\mathrm{PO}_{4}{ }^{3-}$ removal capacity from aqueous solution and adequacy of the model was evaluated using regression analysis and analysis of variance. The model predicted maximum $\mathrm{PO}_{4}{ }^{3-}$ removal capacity of the AC/NZVI was $152.12 \mathrm{mg} \mathrm{g}^{-1}$ under the optimal

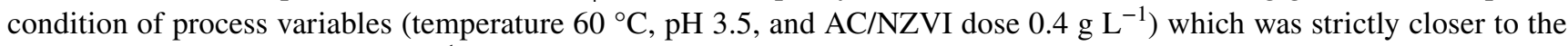
experimental value $\left(151.10 \mathrm{mg} \mathrm{g}^{-1}\right.$ ) obtained in batch experiment under the same optimize condition of process variables. The result of the study inferred that all three factors had a significant impact on removal of $\mathrm{PO}_{4}{ }^{3-}$.
\end{abstract}

Keywords Activated carbon · AC/NZVI · Phosphate removal · Optimization · Box-Behnken experimental design · Quadratic model

\section{Introduction}

Phosphorus $(\mathrm{P})$ is highly significant for growth of organism and plants in ecosystem and also in industry (Zhang et al. 2017). In natural streams of water, phosphorous is present in phosphate $\left(\mathrm{PO}_{4}{ }^{3-}\right)$ form. It is very essential resource for agricultural and industrial products (You et al. 2016). However, water quality becomes affected due to huge application of detergents, synthetic fertilizers as well as animal-based fertilizers, pigment formulation etc. which produces high

Arun K. Singh

aruniitr09@gmail.com

1 Environmental Chemistry Division, CSIR- Indian Institute of Toxicology Research, Post Box 80, Mahatma Gandhi Marg, Lucknow 226001, India

2 Present Address: Department of Chemical Engineering, Indian Institute of Technology Kanpur, Kanpur 208016, India amount of phosphate in aqueous streams. The presence of $\mathrm{P}$, less than $1 \mathrm{mg} / \mathrm{L}$ from municipalities and industries is often responsible for eutrophication in receiving water bodies (Zhang et al. 2009). Quality and sustainability of aqueous streams is affected by eutrophication which is one of the severe problems worldwide. Reduction level of oxygen in an aqueous stream can be caused by eutrophication which rises environmental degradation and produces substantial financial effects on drinking water supplies and fisheries (Singh and Singh 2016). Thus, it is of great importance to develop simplest and efficient method in order to remediate the water contaminated with $\mathrm{PO}_{4}{ }^{3-}$.

Nanoscale zero-valent iron (NZVI) have been widely used in various studies for the decontamination of water. It was recognized to be an auspicious adsorbent in the treatment of water contaminated with Cr (VI) (Singh et al. 2011), As (V) (Du et al. 2014), Cd (II) (Boparai et al. 2011), nitrate (Singh et al. 2012a) and $\mathrm{PO}_{4}{ }^{3-}$ (Almeelbi and Bezbaruah 2012) and halogenated organic compound (Xu et al. 2013). Low-cost, 
low noxious, small footprint and easy to get are some of the advantages of material which can fulfill the requirements for environmental remediation application. The techniques of NZVI are very effective in treatment of both organic and inorganic contaminants (Sleiman et al. 2016; Liu and Lowry 2006). In situ and ex situ applications, iron nanoparticles provide enormous flexibility and were also proved as a sensitive material in permeable reactive barriers. However, there are still some problems associated with practical applications of nanoparticles such as nanoparticles tend to aggregate and suffer from the absence of robustness under oxic conditions and mechanical strength (Sleiman et al. 2016). In addition, without any proper supportive materials, a direct use of NZVI in water remediation application causes iron pollution in water as well as also loses its efficiency due to its tiny particle size. Hence, in order to avoid these issues, it is very important to load NZVI onto proper supporting materials for the treatment of contaminated water (Zhu et al. 2009). Large surface area, high surface reactivity, and pore size distribution make activated carbon as widely used adsorbent for water and advanced wastewater treatment. When activated carbon modified by iron, it can be an excellent adsorbent and also exhibit magnetic behavior. Due to this ability, under an external magnetic field, these are easily separable from the liquid phase (Lv et al. 2012). To prepare activated carbon supported NZVI (AC/NZVI) and analyze its effectiveness in $\mathrm{PO}_{4}{ }^{3-}$ removal from water were the objectives of this study. Activated carbon was chosen as supporting materials for NZVI because of its porous structure and excellent properties in mechanical strength.

Besides the development of supported NZVI, effective removal of ions from water depends on several process variables such as temperature, initial $\mathrm{pH}$ of the solution, dose of the applied nanoparticles or adsorbent and contact time. Zhang et al. (2009) investigated the removal of phosphate from water using $\mathrm{Fe}-\mathrm{Mn}$ binary oxide adsorbent. This adsorbent was synthesized by oxidation and co-precipitation process. Authors evaluated effect of contact time, effect of $\mathrm{pH}$, initial phosphate concentrations and effect of coexisting anions on the adsorption of phosphate. In this study, it was observed that the removal of phosphate from aqueous solution by this oxide was highly $\mathrm{pH}$ dependent. In addition, Wang et al. (2011) studied the adsorption of phosphate onto activated carbon modified by iron from aqueous solution. They also observed that temperature and initial $\mathrm{pH}$ of the solution have significant effects on the removal of phosphate. Thus, in order to get best removal efficiency of the adsorbent, it is very essential to optimize the selected significant removal process variables. However, no attempt has been made so far for the optimization of the independent process variables such as initial $\mathrm{pH}$, temperature, dose of the nanoparticles for maximizing the $\mathrm{PO}_{4}{ }^{3-}$ removal efficiency using AC/NZVI.
Optimization of process variables using conventional approach, where only one parameter is varied at a time and all others parameters remain constant, consumes more time and requires a lot of experiments number in order to get optimum levels of process variables (Singh et al. 2011). Thus, such type of optimization approach increases the experimental cost as well as also fails in assessment of cumulative effect of selected variables of removal process simultaneously. Such type of problems can be overcome by the consideration of the statistical experimental design approach. Nowadays, several experimental methods have been used in multiple variable optimizations (Singh et al. 2012b). Response surface modeling (RSM) is one of the popular statistical techniques which is generally used for optimization of process analysis and modeling. Application of RSM, in removal process, offers several advantages such as low experimental cost and high precision in prediction of optimum level of each variable. However, no information available in the literature related to the optimization of $\mathrm{PO}_{4}{ }^{3-}$ removal by AC/NZVI. Therefore, the main aim of this study was to synthesize and characterize the application of AC/NZVI and evaluate the maximum efficiency for $\mathrm{PO}_{4}{ }^{3-}$ removal from water streams using Box-Behnken design (BBD) under RSM.

\section{Experimental}

\section{Materials}

All chemicals and reagents used in the study were of AR grade. By dissolving the required amount of potassium dihydrogen phosphate $\left(\mathrm{KH}_{2} \mathrm{PO}_{4}\right)$ in distilled water, stock solution of $\mathrm{PO}_{4}{ }^{3-}$ was prepared. Stock solution of $\mathrm{PO}_{4}{ }^{3-}$ were further diluted into desired concentration of $\mathrm{PO}_{4}{ }^{3-}$. All chemicals were obtained in purity $>99 \%$. Diluted hydrochloric acid $(\mathrm{HCl})$ and sodium hydroxide $(\mathrm{NaOH})$ were used in order to adjust the desired $\mathrm{pH}$ of the test solutions.

\section{Preparation of Ac/NZVI}

The activated carbon used as supporting materials for NZVI was prepared from raw materials cork powder waste. Method for preparation of cork activated carbon (CAC) is described elsewhere (Mestre et al. 2007). Briefly, the CAC was prepared by treating cork powder and $\mathrm{K}_{2} \mathrm{CO}_{3}$ in a ratio of $1: 1(\mathrm{w} / \mathrm{w})$ and same were kept in furnace for calcinations. Temperature was raised up to $700{ }^{\circ} \mathrm{C}$ in the presence of nitrogen flow at the rate of $10^{\circ} \mathrm{C} \mathrm{min}-1$ and remains $1 \mathrm{~h}$ in furnace. Prepared product was cooled down unto the room temperature in the presence of nitrogen atmosphere. Prepared material was then washed properly with distilled water until $\mathrm{pH} 7$ and dried at $100^{\circ} \mathrm{C}$.

By reducing ferric ion $\left(\mathrm{FeCl}_{3}\right)$ to $\mathrm{Fe}^{0}$ using borohydride $\left(\mathrm{NaBH}_{4}\right)$ reduction method, activated carbon supported 
zero-valent iron (AC/NZVI) was prepared (Zhu et al. 2009). Firstly, one gram of CAC was equilibrated with $30 \mathrm{~mL}$ $1.0 \mathrm{M} \mathrm{N}_{2}$-purged ferric chloride solution for $3 \mathrm{~h}$. Then, the slurry was diluted up to $100 \mathrm{~mL}$ using a mixture of ethanol and deionized water (v/v 70:30). $100 \mathrm{~mL}$ of $1.0 \mathrm{M} \mathrm{NaBH}_{4}$ was added dropwise (30-40 drop/min) into the slurry at $25{ }^{\circ} \mathrm{C}$ with magnetic stirring and $\mathrm{N}_{2}$ bubbling. Ferric ion was reduced to zero-valent iron according to the following reaction.

$4 \mathrm{Fe}^{3+}+3 \mathrm{BH}_{4}^{-}+9 \mathrm{H}_{2} \mathrm{O} \rightarrow 4 \mathrm{Fe}^{0} \downarrow+3 \mathrm{H}_{2} \mathrm{BO}_{3}^{-}+12 \mathrm{H}^{+}+6 \mathrm{H}_{2} \uparrow$

After agitation of $30 \mathrm{~min}$, via vacuum filtration, $\mathrm{AC} /$ NZVI was separated from the liquid phase; in order to clean up the residual reagent on AC/NZVI particles, it was further washed three times with the help of ethanol and the resulting black solid vacuum-dried at $45^{\circ} \mathrm{C}$, and stored in $\mathrm{N}_{2}$-purged desiccator.

\section{Characterization of ZVINPs}

The surface morphologies of the developed bimetallic particles were investigated using SEM, ZEISS, model SUPRA VP 40 (Germany). The X-ray diffraction (XRD) pattern of AC/ NZVI was determined using X-ray diffractometer (Panalytical $\mathrm{X}$ 'pert Pro) at $40 \mathrm{kV}$ and $30 \mathrm{~mA}$. The instrument used copper $\mathrm{K} \alpha$ radiation $(\lambda=1.54 \AA)$ to produce $\mathrm{X}$-rays with a wavelength of $1.54060 \AA$. Fourier transform infrared spectroscopy (FTIR) of the activated carbon was obtained using the Perkin Elmer FTIR model RX1 (USA)in the range of $4000-450 \mathrm{~cm}^{-1}$. Magnetic properties were analyzed using a vibrating sample magnetometer (EV 7 VSM, USA) with a magnetic field of 17.5 KOe. The BET specific surface area $\left(\mathrm{S}_{\mathrm{BET}}\right)$ was measured using the nitrogen absorption method with Autosorb-1C (Quantachrome, USA) surface area analyzer.

\section{Batch experimental procedures}

Batch experiments of $\mathrm{PO}_{4}{ }^{3-}$ removal based on $\mathrm{BBD}$ were featured to investigate the effects of the selected process variables such as initial $\mathrm{pH}$, temperature $(\mathrm{T})$ and $\mathrm{AC} / \mathrm{NZVI}$ dose (D) on $\mathrm{PO}_{4}{ }^{3-}$ removal by AC/NZVI in aqueous medium. $\mathrm{A}$ number of conical flasks containing $50 \mathrm{~mL}$, in each conical, of $\mathrm{PO}_{4}{ }^{3-}$ solution of fixed concentration were placed in a thermo-controlled $\left( \pm 1^{\circ} \mathrm{C}\right)$ water bath shaker for $1 \mathrm{~h}$ at $120 \mathrm{rpm}$ at pre-decided temperatures $\left(20-60{ }^{\circ} \mathrm{C}\right)$ to achieve equilibrium during the experiment. On the basis of the result obtained from preliminary experiments, the contact time was selected. When the desired temperature reached, a fixed amount of the material was added to each flask and the solutions were shacked agitated mechanically. At predecided intervals of time, the solutions of the conical flasks were separated from AC/NZVI by filtration using $0.2 \mu \mathrm{m}$ polyethersulfone (PES), syringe filter and further analyzed using spectrophotometric method to determine the amount of $\mathrm{PO}_{4}{ }^{3-}$ left in solution. All batch experiments were performed in triplicate, and the mean of them was taken for all calculations.

\section{Analytical methods}

Using spectrophotometric measurement (Perkin Elmer UV-visible spectrophotometer model Lambda-35), the initial and final concentrations of $\mathrm{PO}_{4}{ }^{3-}$ in the solution were determined Absorbance values were recorded at the wavelength $690 \mathrm{~nm}$ by adding molybdate reagent. The $\mathrm{PO}_{4}{ }^{3-}$ concentration was measured using UV-Visible spectrophotometer with a 1-cm light-path cell, with an absorbance accuracy of \pm 0.004 at $\lambda_{\max }$. Using pH meter (Model 744, Metrohm, Switzerland), $\mathrm{pH}$ measurements were made and initial $\mathrm{pH}$ of the solution were adjusted using dilute hydrochloric acid or sodium hydroxide solution. Removal capacity of $\mathrm{PO}_{4}{ }^{3-}$, $q_{\mathrm{e}}\left(\mathrm{mg} \mathrm{g}^{-1}\right)$ of the AC/NZVI was calculated as (Singh et al. 2012a);

$q_{\mathrm{e}}=\frac{\left(C_{0}-C_{\mathrm{e}}\right) V}{W}$

where $C_{\mathrm{o}}$ is the initial concentration $\left(\mathrm{mg} \mathrm{l}^{-1}\right)$, and $C_{\mathrm{e}}$ is the final concentration $\left(\mathrm{mg} \mathrm{l}^{-1}\right)$ of $\mathrm{PO}_{4}{ }^{3-}$ in solution. The $V$ represents the solution volume $(L)$, and $W$ represents the weight of the AC/NZVI particles $(g)$, respectively.

\section{BBD for experimental design approach and optimization}

The combination of RSM with the experimental design is a very useful technique in order to evaluate the interaction among selected variables and optimize the variables with the save time and reduce cost. Herein, BBD, which is the most popular experimental design in RSM, was utilized to optimize the selected phosphate removal parameters. The three parameters known to have a significant effect on removal of phosphate such as temperature $(T)$, solution $\mathrm{pH}$ and dose of AC/NZVI composite were selected as independent process variables and each them was at three levels. The highest, lowest and middle levels of the selected independent process variables were coded as 1, 0 and - 1, respectively (Singh and Singh 2016). Thus, on the basis of three-factor threelevel BBD, a total of 15 experimental set were produced using the following equation:

$N=2 k(k-1)+C_{0}$.

where $N$ is the total number of experiments, $C_{0}$ is a number of replication of experiments at central points to define the experimental error, and $k$ is the number of selected independent variables for optimization of removal process. In 
general, 3-6 center points are recommended for experimental sets with BBD (Singh et al. 2012b). In this study, 3 center points were taken in total of 15 experimental sets. The range, limits, units and notations of the selected variables are given in Table 1. Due to the three levels of each factor, a mathematical relationship between them was fitted to quadratic polynomial model as follows (Eq. 3) for the prediction of phosphate removal capacity under a certain set of experimental condition.

$Y=\beta_{0}+\sum_{i=1}^{n} \beta_{i} X_{i}+\sum_{i=1}^{n} \beta_{i i} X_{1}^{2}+\sum_{i=1}^{n} \sum_{j=1}^{n} \beta_{i j} X_{i} X_{j}+e$

where $Y$ is the predicted removal capacity as a response, $\beta_{0}$ is the model constant, $\beta_{i}, \beta_{i j}$ and $\beta_{i i}$ are the linear, interaction and quadratic coefficient terms, respectively. The $X_{i}, X_{j}$ are coded form of the values of the selected process variables, and e represents the model error.

The above equation (Eq. 3) further can be expressed more clearly by the addition of name of each selected process variables in the place of $X_{i}$ and $X_{j}$. Thus, the quadratic polynomial model for the $\mathrm{PO}_{4}{ }^{3-}$ removal capacity $\left(\mathrm{mg} \mathrm{g}^{-1}\right)$ of the developed AC/NZVI in terms of response variable $(Y)$ can be expressed as:

$$
\begin{aligned}
Y & =\beta_{0}+\beta_{1} X_{\mathrm{T}}+\beta_{2} X_{\mathrm{T}}^{2}+\beta_{3} X_{\mathrm{pH}}+\beta_{4} X_{\mathrm{pH}}^{2}+\beta_{5} X_{\mathrm{D}} \\
& +\beta_{6} X_{\mathrm{D}}^{2}+\beta_{7} X_{\mathrm{T}} X_{\mathrm{pH}}+\beta_{8} X_{\mathrm{T}} X_{\mathrm{D}}+\beta_{9} X_{\mathrm{pH}} X_{\mathrm{D}}
\end{aligned}
$$

where $X_{\mathrm{T}}, X_{\mathrm{pH}}$, and $X_{\mathrm{D}}$ are the coded form of the selected process variables (temperature, initial $\mathrm{pH}$ of solution, and AC/NZVI dose). Equation 4 was analyzed for the data obtained using Design Expert 8.0.7.1 (trial version), and the regression model was proposed. The model coefficients $\left(\beta_{i}\right)$ were estimated in order to predict the response $(Y)$ as phosphate removal capacity at different combinations of the coded values of the variables.

The analysis of variance (ANOVA) of the quadratic model was utilized to evaluate the adequacy of the proposed model and to identify the significance of significance of the independent variables and their interactions. In addition, fit quality of the developed quadratic model was evaluated by the coefficient of determination $\left(R^{2}\right)$, the root-mean-square error of prediction (RMSEP), and the relative standard error of prediction (RSEP) (Singh et al. 2010, 2012b).

\section{Response optimization}

The developed quadratic model was used to select the optimum conditions of the independent variables within their experimental ranges for achieving maximum removal of $\mathrm{PO}_{4}{ }^{3-}$ from aqueous solution by AC/NZVI. In order to justify the good prediction ability of the model for $\mathrm{PO}_{4}{ }^{3-}$ removal, five experiments sets were carried out as replicates at the optimum conditions of variables predicted by the model.

\section{Results and discussion}

\section{Characterization of ZVINPs}

The SEM image of AC and AC/NZVI is shown in Fig. 1a, b. It could be seen that nanoparticles were roughly circular and also having coarse and rough morphology. The AC maintains the high surface area and reactivity by preventing the agglomeration of metal particles. From the figure, it is clear that on the surface, the metal particles are well attached. The size of AC/NZVI was in the range of 20-60 nm in diameter. The course and rough morphology of nanoparticles provides sites having high reactivity than the smooth morphology and, thereby, was in favor of removal process by AC/NZVI in aqueous solution (Singh et al. 2011).

The XRD pattern of ZVINPs is shown in Fig. 2. The peak in the XRD pattern is relatively broad because of the small size of particles. The diffraction peak at $2 \theta$ of $44.7^{\circ}$ as shown in Fig. 2 corresponds to the existence of the iron in its zero valent $(\mathrm{Fe})$.

The rate of reaction and kinetics of the system are significantly influenced by the surface area of the adsorbent in water remediation process. When available surface area is increased, more reactive sites are available. The porous structure of the activated carbon was significantly altered after the loading of NZVI. The surface area of AC and AC/NZVI was found to be $335 \mathrm{~m}^{2} \mathrm{~g}^{-1}$ and $88.29 \mathrm{~m}^{2} \mathrm{~g}^{-1}$, respectively. The surface area of AC/NZVI was lower in
Table 1 Process variables, their coded values and limits

\begin{tabular}{lllllll}
\hline Variable & Notation & Unit & Limits & & $\begin{array}{l}\text { Step } \\
\text { change } \\
\text { value, } \Delta x i\end{array}$ \\
\hline Temperature & & & -1 & 0 & +1 & 20 \\
Initial pH of the solution & $\mathrm{T}$ & ${ }^{\circ} \mathrm{C}$ & 20 & 40 & 60 & 2.5 \\
AC/NZVI dose & $\mathrm{DH}$ & - & 3.5 & 5.0 & 6.5 & 1.5 \\
\hline
\end{tabular}




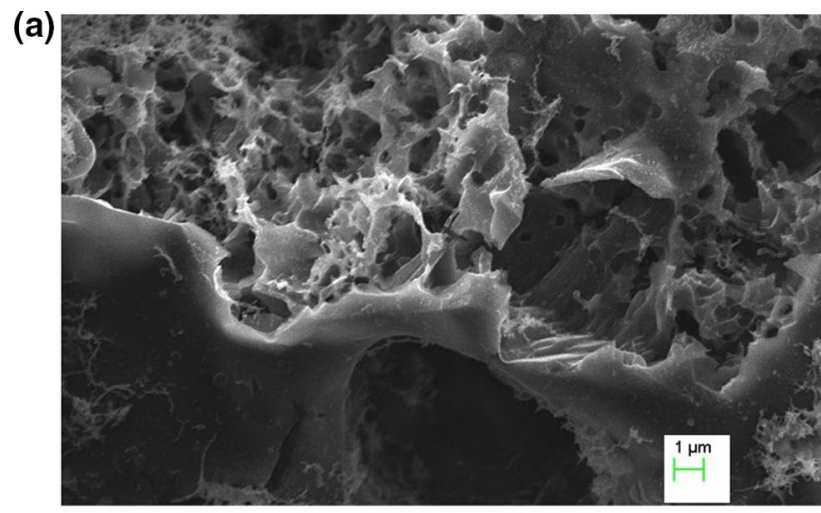

(b)

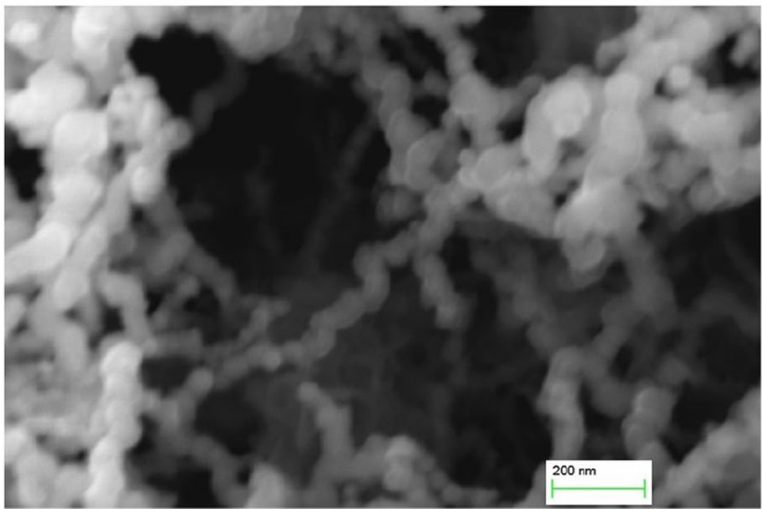

Fig. 1 a SEM Image of AC, b SEM Image of AC/NZVI nanoparticle

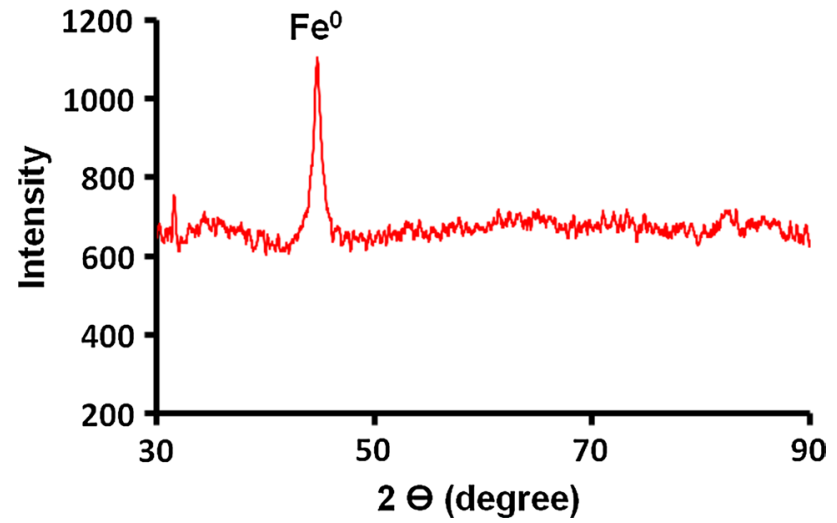

Fig. 2 X-ray diffractogram (XRD) of AC/NZVI

comparison with the $\mathrm{AC}$; this observation inferred that after the loading of NZVI, most of the pores of AC were blocked.

\section{Response surface optimization}

\section{BBD experiments, model results and statistical analysis}

The experiments sets were carried out according to the BBD program to designate the maximum phosphate removal capacity $\left(\mathrm{mg} \mathrm{g}^{-1}\right)$ of the AC/NZVI from aqueous solution and to evaluate the interactive and individual effects of the selected variables (temperature, solution $\mathrm{pH}$ and $\mathrm{AC} / \mathrm{NZVI}$ dose) on removal of $\mathrm{PO}_{4}{ }^{3-}$ by AC/NZVI. Table 2 exhibits the $\mathrm{PO}_{4}{ }^{3-}$ removal efficiency of the AC/NZVI from aqueous solution for each of the experiment sets as created by BBD along with the predicted removal results. The maximum removal capacity of the AC/NZVI for $\mathrm{PO}_{4}{ }^{3-}$ was observed to be $140.58 \mathrm{mg} \mathrm{g}^{-1}$.

The final model equation obtained by the program proposed $\mathrm{PO}_{4}{ }^{3-}$ removal $\left(\mathrm{mg} \mathrm{g}^{-1}\right)$ with regard to real values of three selected variables as pointed out in Eq. (5).

$$
\begin{aligned}
& Y\left(\mathrm{mg} \mathrm{g}^{-1}\right)=78.243+9.885 X_{\mathrm{T}}-0.789 X_{\mathrm{T}}^{2} \\
& \quad-26.129 X_{\mathrm{pH}}-10.507 X_{\mathrm{pH}}^{2}-22.286 X_{\mathrm{D}}+3.338 X_{\mathrm{D}}^{2} \\
& \quad+2.078 X_{\mathrm{T}} X_{\mathrm{pH}}-9.473 X_{\mathrm{T}} X_{\mathrm{D}}+16.140 X_{\mathrm{pH}} X_{\mathrm{D}}
\end{aligned}
$$

The statistical significance of each term in the developed quadratic model and interaction effect of selected variables on removal of $\mathrm{PO}_{4}{ }^{3-}$ by the AC/NZVI system are expressed in the ANOVA table (Table 3 ). The $F$ and $P$ values were used to decide the significance of variables. The larger $F$ values $\left(F_{\text {model }}=37.62\right)$ and very low $P$ value $\left(p_{\text {model }}=0.0005\right)$ suggested that this quadratic regression model is statistically significant. In addition, goodness-of-fit of the model was also evaluated by the coefficient of determination $\left(R^{2}\right)$ and adjusted correlation coefficient $\left(R_{\text {adj }}^{2}\right.$ ). The $R^{2}$ was calculated by the use of $\mathrm{PO}_{4}{ }^{3-}$ removal capacity of as-obtained AC/NZVI by all experimental data and capacity predicted by the developed quadratic model (Fig. 3). The value of $R^{2}$ observed in this study is 0.985 which is in reasonable agreement with the Adj R-Squared ( $\left.R_{\text {adj }}^{2}, 0.959\right)$. This high value of $R^{2}$ indicates higher capability of this model because present model is able to explain $98.5 \%$ of the experimental results for the selected variables (temperature, solution $\mathrm{pH}$ and $\mathrm{AC} / \mathrm{NZVI}$ dose).

In addition, the adequacy of the quadratic model was also assessed in terms of the RMSE and RSEP. As a result, a considerably low RMSEP (3.45) and RSEP (0.435) values indicate that this quadratic model is acceptable for prediction of optimum condition of selected variables (Singh et al. 2011, 2012b; Yetilmezsoy and Saral 2007).

\section{Effects of model components and their interactions on $\mathrm{PO}_{4}{ }^{3-}$ removal}

The linear, quadratic and interactive coefficients of quadratic model were evaluated in terms of significant and nonsignificant by the use of Student's $t$ test and $p$ values. The results of $p$ and $t$ test values are shown in Tables 3 and 4, respectively. It has been reported that in the regression model the smaller magnitude of the $p$ value and larger the $t$ value is two essential factor for a parameter to be 
Table 2 BBD matrix with four independent variables [actual (A) and coded(C) values] and corresponding experimental and predicted removal (in $\mathrm{mg} \mathrm{g}^{-1}$ ) of $\mathrm{PO}_{4}{ }^{3-}$

\begin{tabular}{|c|c|c|c|c|c|c|c|c|}
\hline \multirow[t]{2}{*}{ Exp. no. } & \multicolumn{2}{|c|}{ Temperature $\left({ }^{\circ} \mathrm{C}\right)$} & \multicolumn{2}{|l|}{$\mathrm{pH}$} & \multicolumn{2}{|c|}{ Dose $\left(\mathrm{g} \mathrm{L}^{-1}\right)$} & \multicolumn{2}{|c|}{ Removal $\left(\mathrm{mg} \mathrm{g}^{-1}\right)$} \\
\hline & A & $\mathrm{C}$ & A & $\mathrm{C}$ & A & $\mathrm{C}$ & Experimental & Predicted \\
\hline 1 & 20 & -1 & 3.5 & -1 & 0.8 & 0 & 82.72 & 85.27 \\
\hline 2 & 60 & 1 & 3.5 & -1 & 0.8 & 0 & 94.72 & 100.88 \\
\hline 3 & 20 & -1 & 6.5 & 1 & 0.8 & 0 & 34.97 & 28.86 \\
\hline 4 & 60 & 1 & 6.5 & 1 & 0.8 & 0 & 55.33 & 52.78 \\
\hline 5 & 20 & -1 & 5.0 & 0 & 0.4 & -1 & 81.32 & 83.72 \\
\hline 6 & 60 & 1 & 5.0 & 0 & 0.4 & -1 & 123.6 & 122.44 \\
\hline 7 & 20 & -1 & 5.0 & 0 & 1.2 & 1 & 56.93 & 58.09 \\
\hline 8 & 60 & 1 & 5.0 & 0 & 1.2 & 1 & 61.32 & 58.92 \\
\hline 9 & 40 & 0 & 3.5 & -1 & 0.4 & -1 & 140.58 & 135.63 \\
\hline 10 & 40 & 0 & 6.5 & 1 & 0.4 & -1 & 47.38 & 51.09 \\
\hline 11 & 40 & 0 & 3.5 & -1 & 1.2 & 1 & 62.49 & 58.78 \\
\hline 12 & 40 & 0 & 6.5 & 1 & 1.2 & 1 & 33.85 & 38.80 \\
\hline 13 & 40 & 0 & 5.0 & 0 & 0.8 & 0 & 78.61 & 78.24 \\
\hline 14 & 40 & 0 & 5.0 & 0 & 0.8 & 0 & 78.21 & 78.24 \\
\hline 15 & 40 & 0 & 5.0 & 0 & 0.8 & 0 & 77.91 & 78.24 \\
\hline
\end{tabular}

Table 3 ANOVA of the response surface quadratic model for the prediction of aqueous $\mathrm{PO}_{4}{ }^{3-}$ removal by $\mathrm{AC} /$ NZVI

\begin{tabular}{lrrrrrr}
\hline Source & Sum of squares & $d f^{*}$ & $\begin{array}{l}\text { Mean sum of } \\
\text { squares }\end{array}$ & $F$ value & $P$ value & Remarks \\
\hline Model & $12,106.73$ & 9 & 1345.19 & 37.62 & 0.0005 & Significant \\
$X_{\mathrm{T}}$ & 781.71 & 1 & 781.71 & 21.86 & 0.0055 & Significant \\
$X_{\mathrm{T}}^{2}$ & 2.30 & 1 & 2.30 & 0.06 & 0.8099 & \\
$X_{\mathrm{pH}}$ & 5661.69 & 1 & 5661.69 & 152.73 & 0.0001 & Significant \\
$X \mathrm{pH}^{2}$ & 407.59 & 1 & 407.59 & 11.40 & 0.0198 & Significant \\
$X_{\mathrm{D}}$ & 3973.42 & 1 & 3973.42 & 111.11 & 0.0001 & Significant \\
$X_{\mathrm{D}}^{2}$ & 41.15 & 1 & 41.15 & 1.15 & 0.3324 & \\
$X_{\mathrm{T}} \times X_{\mathrm{pH}}$ & 17.26 & 1 & 17.26 & 0.48 & 0.5181 & \\
$X_{\mathrm{T}} \times X_{\mathrm{D}}$ & 358.91 & 1 & 358.91 & 10.04 & 0.0249 & Significant \\
$X \mathrm{pH} \times X_{\mathrm{D}}$ & 1042.00 & 1 & 1042.00 & 29.14 & 0.0029 & Significant \\
Error & 178.81 & 5 & 35.76 & & & \\
Lack of fit & 178.56 & 3 & 59.52 & 482.59 & 0.0031 & Significant \\
Pure error & 0.25 & 2 & 0.12 & & & \\
Total & $12,285.54$ & 14 & & & & \\
\hline
\end{tabular}

* $D F$ degrees of freedom significant (Meng et al. 2007; Shao-Feng et al. 2005). As shown in Table 3, except $T^{2}$ and $D^{2}$, all the linear and quadratic terms are statistically significant with the $\mathrm{p}$ value lower than 0.02. $(p<0.05)$. Moreover, among all three interactive terms, $X_{\mathrm{T}} \times X_{\mathrm{D}}$ and $X_{\mathrm{pH}} \times X_{\mathrm{D}}$ were found statistically significant, while $X_{\mathrm{T}} \times X_{\mathrm{pH}}$ was not significant. Thus, it can be concluded that $\mathrm{PO}_{4}{ }^{3-}$ removal capacity of AC/NZVI was strongly influenced by the selected process variables such as temperature (T), $\mathrm{pH}$ and AC/NZVI dose (D). A broad range of variation in $\mathrm{PO}_{4}{ }^{3-}$ removal efficiency was observed in terms of response factor (33.85-140.58 $\left.\mathrm{mg} \mathrm{g}^{-1}\right)$ in the experimental batch study.
In addition, the standardized effects of the selected process variables and their interactions on the $\mathrm{PO}_{4}{ }^{3-}$ removal efficiency of AC/NZVI were investigated by the Pareto chart analysis. The Pareto chart is shown in Fig. 4, which is significantly helpful to investigate the results.

It was observed that the initial $\mathrm{pH}$ of the test solutions offered the largest effect on $\mathrm{PO}_{4}{ }^{3-}$ removal process. A similar trend is also exhibited by the regression coefficients in quadratic model Eq. (5). The percent contribution (PC) is the ratio of SS of an individual term to that of sum of SS for all the terms in final quadratic model (Singh et al. 2011; Yetilmezsoy and Saral 2007), as 


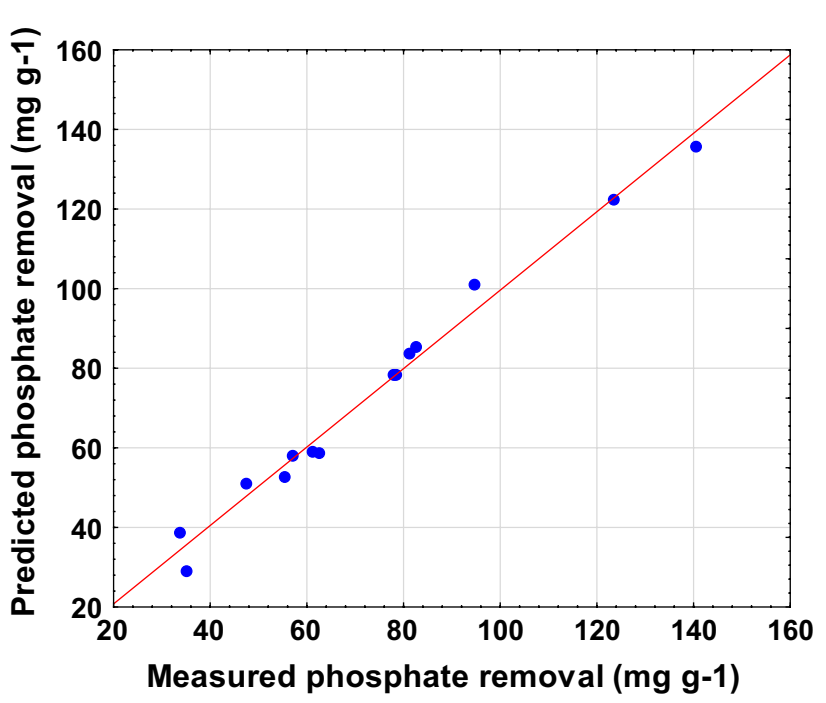

Fig. 3 Plot of the measured and model predicted values of the response variable

$\mathrm{PC}=\frac{\mathrm{SS}}{\sum \mathrm{SS}} \times 100$

The PC values for all the term of the final model was computed, and results are shown in Table 4.

It is evident from Table 4 that, as computed to other components, $\mathrm{pH}$ of the test solution showed the highest level of significance with a contribution of $>45$.

\section{Three-dimensional response surface plots}

In order to clarify the effect of selected process variables on efficiency in removal of $\mathrm{PO}_{4}{ }^{3-}$, the three-dimensional (3D) surface curves were plotted based on the quadratic model with two factors for each graph and their response (Fig. 5a-c) (Singh et al. 2012b; Yetilmezsoy and Saral 2007). The combined effect of temperature (20, 40 and $\left.60{ }^{\circ} \mathrm{C}\right)$ and solution $\mathrm{pH}\left(3.5,5.0\right.$ and 6.5) on $\mathrm{PO}_{4}{ }^{3-}$ removal efficiency at constant AC/NZVI dose of $0.8 \mathrm{~g} \mathrm{~L}^{-1}$ is exhibited in Fig. 5a. The $\mathrm{PO}_{4}{ }^{3-}$ removal efficiency of AC/NZVI increases with increasing temperature, whereas, declines with increase in initial $\mathrm{pH}$ of solution within their selective experimental range of variables. Such a behavior of effect of temperature may be understood that an increase in temperature would enhance mobilization of the reacting species (Singh et al. 2011). However, effect of pH is well rational with the assumption that solid surface acquired positive/negative surface charge in solution during removal process (Zhu et al. 2009). It has been reported that AC/NZVI surface acquires positive charge at $\mathrm{pH}$ below the point of zero-charge (' 7.2) and negatively charged at $\mathrm{pH}$ higher than the point of zero-charge. Thus, with the increase in initial $\mathrm{pH}$ of $\mathrm{PO}_{4}{ }^{3-}$ solution, the positive charge on the AC/NZVI surface has become reduced and does not favor the adsorption of $\mathrm{PO}_{4}{ }^{3-}$ due to electrostatic repulsion (Shao-Feng et al. 2005). A maximum

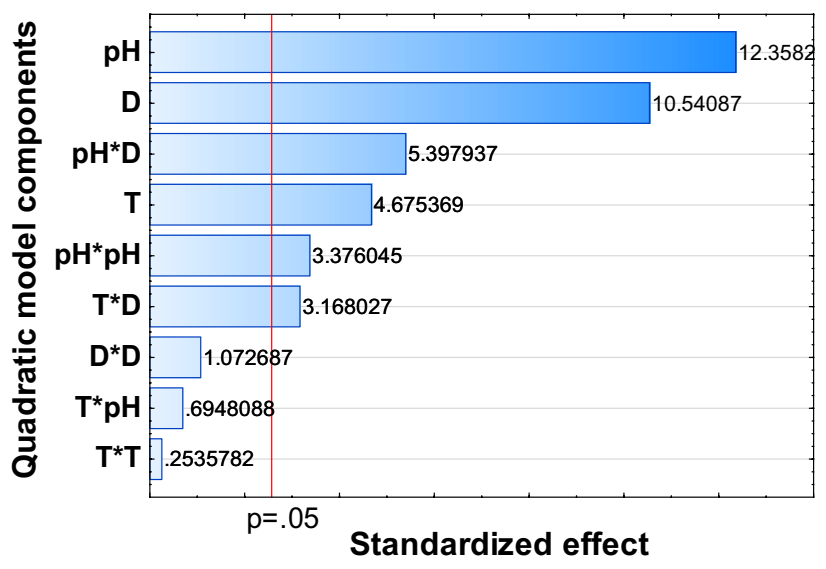

Fig. 4 Pareto chart showing the standardized effect of independent variables and their interaction on $\mathrm{PO}_{4}{ }^{3-}$ removal efficiency
Table 4 Multiple regression results and significance of the components for the quadratic model

\begin{tabular}{llrrrrr}
\hline Factor (Coded) & Parameter & Coefficient & sum of squares & SE & $t$ value & PC* \\
\hline Intercept & $\beta_{\mathrm{o}}$ & 78.243 & \multicolumn{1}{c}{-} & 3.453 & 22.662 & \\
$\mathrm{X}_{\mathrm{T}}$ & $\beta_{1}$ & 9.885 & 781.71 & 2.114 & 4.6754 & 6.47 \\
$\mathrm{X}_{\mathrm{T}}^{2}$ & $\beta_{2}$ & -0.789 & 2.30 & 3.112 & -0.2536 & 0.02 \\
$\mathrm{XpH}$ & $\beta_{3}$ & -26.129 & 5661.69 & 2.114 & -12.358 & 45.19 \\
$\mathrm{XpH}^{2}$ & ${ }_{4}$ & -10.507 & 407.59 & 3.112 & -3.376 & 3.37 \\
$\mathrm{X}_{\mathrm{D}}$ & $\beta_{5}$ & -22.286 & 3973.42 & 2.114 & -10.541 & 32.88 \\
$\mathrm{X}_{\mathrm{D}}^{2}$ & $\beta_{6}$ & 3.338 & 41.15 & 3.112 & 1.0727 & 0.34 \\
$\mathrm{X}_{\mathrm{T}} \times \mathrm{XpH}$ & $\mathrm{B}_{7}$ & 2.078 & 17.26 & 2.990 & 0.6948 & 0.14 \\
$\mathrm{X}_{\mathrm{T}} \times \mathrm{X}_{\mathrm{D}}$ & $\mathrm{B}_{8}$ & -9.473 & 358.91 & 2.990 & -3.1680 & 2.97 \\
$\mathrm{XpH} \times \mathrm{X}_{\mathrm{D}}$ & $\mathrm{B}_{9}$ & 16.140 & 1042.00 & 2.990 & 5.3979 & 8.62 \\
\hline
\end{tabular}

*Percent contribution 

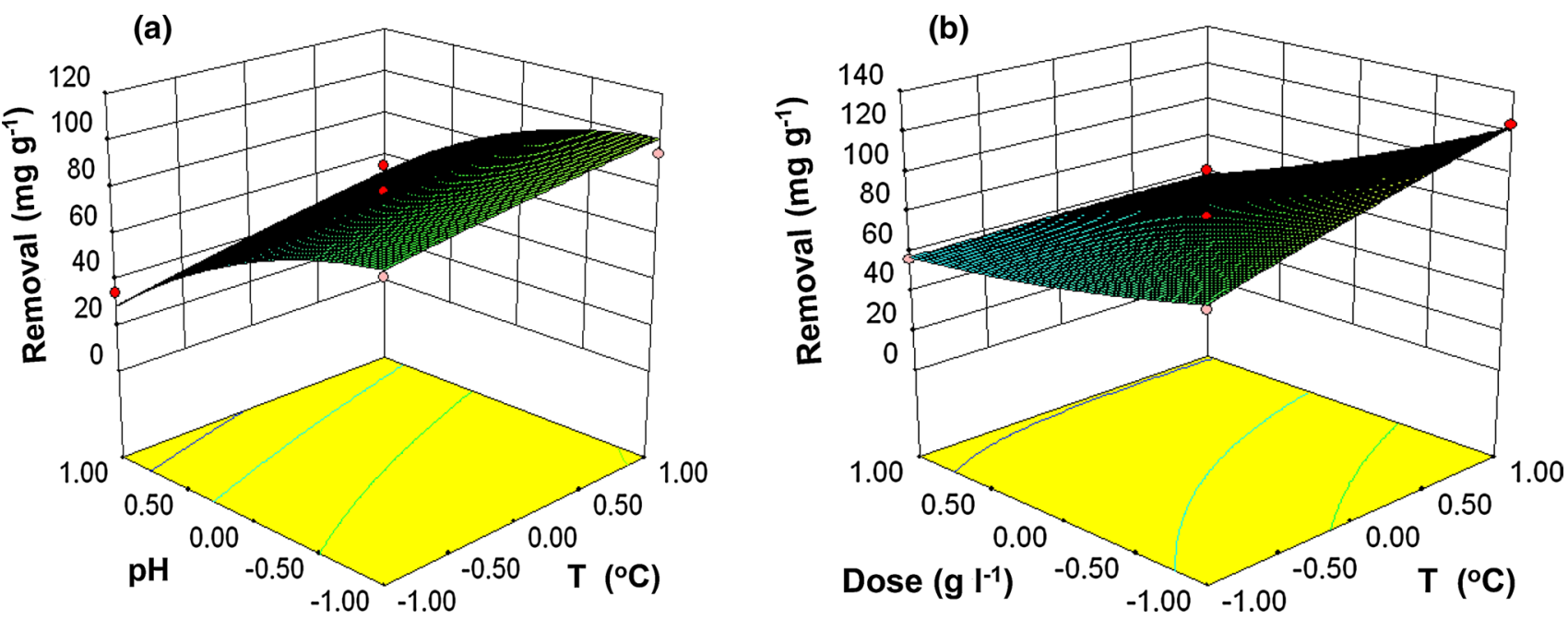

(c)

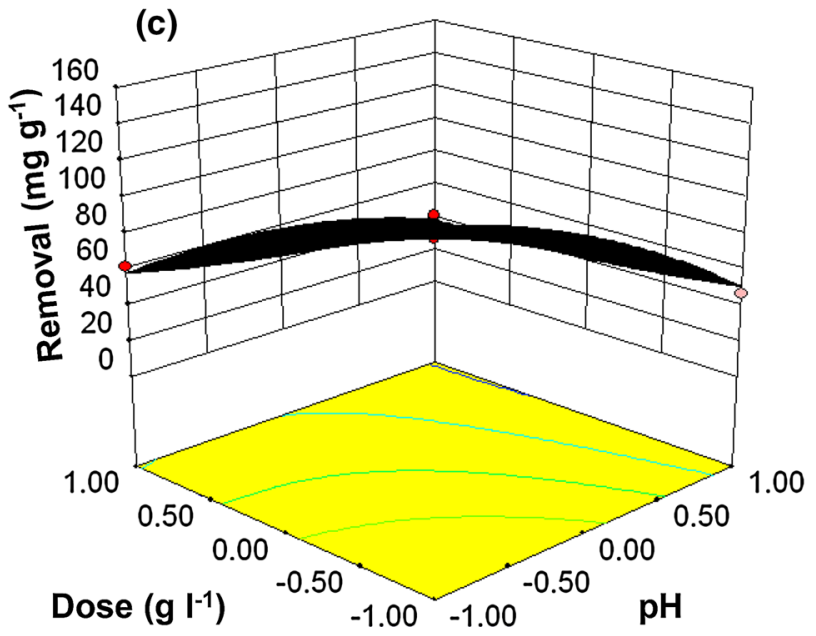

Fig. 5 The response surface plot showing effect of a temperature and solution $\mathrm{pH}, \mathbf{b}$ temperature and nanoparticles dose, $\mathbf{c} \mathrm{pH}$ and nanoparticles dose on phosphate removal by AC/NZVI

$\mathrm{PO}_{4}{ }^{3-}$ removal efficiency was observed as $94.72 \mathrm{mg} \mathrm{g}^{-1}$ at constant AC/NZVI dose of $0.8 \mathrm{~g} \mathrm{~L}^{-1}$. A similar pattern for $\mathrm{PO}_{4}{ }^{3-}$ removal by $\mathrm{Fe}^{0}$ with solution $\mathrm{pH}$ has been reported earlier (Wang et al. 2012).

The interactive effect of AC/NZVI dose $(0.4,0.8$ and $\left.1.2 \mathrm{~g} \mathrm{~L}^{-1}\right)$ and temperature $\left(20,40\right.$ and $\left.60{ }^{\circ} \mathrm{C}\right)$ at constant $\mathrm{pH}$ of $\mathrm{PO}_{4}{ }^{3-}$ solution (5.0) are shown in Fig. 5b. It is evident that $\mathrm{PO}_{4}{ }^{3-}$ phosphate removal decreases with the dose of adsorbent and increases with the temperature in their selected experimental range. This observed behavior may be understood that at higher dose, the nanoparticles in the aqueous medium may agglomerate, reducing the number of active sites on the surface, hence lowering the removal capacity (Singh et al. 2011). The maximum $\mathrm{PO}_{4}{ }^{3-}$ ion removal efficiency was $123.60 \mathrm{mg} \mathrm{g}^{-1}$ at constant $\mathrm{pH}$ of $\mathrm{PO}_{4}{ }^{3-}$ solution (5.0). Figure $5 \mathrm{c}$ shows the interactive influence of $\mathrm{AC} / \mathrm{NZVI}$ dose and initial $\mathrm{pH}$ of solution on removal of $\mathrm{PO}_{4}{ }^{3-}$ from aqueous solution at constant temperature $\left(60^{\circ} \mathrm{C}\right)$. It is evident that $\mathrm{PO}_{4}{ }^{3-}$ removal efficiency declines with these both variables. At this situation of constant temperature maximum, $\mathrm{PO}_{4}{ }^{3-}$ removal of $140.58 \mathrm{mg} \mathrm{g}^{-1}$ was obtained.

\section{Optimum condition of $\mathrm{PO}_{4}{ }^{3-}$ removal and verification}

The optimization of the selected process variables was featured using quadratic model within the range of selected range for removal process. The optimum value of the three selected process variables was predicted by the developed quadratic model as; temperature $60^{\circ} \mathrm{C}$; initial $\mathrm{pH}$ of solution 3.5 and AC/NZVI dose $0.4 \mathrm{~g}^{-1}$ to achieve the maximum removal $\left(152.11 \mathrm{mg} \mathrm{g}^{-1}\right)$ of the $\mathrm{PO}_{4}{ }^{3-}$ in aqueous solution. The model predicted removal efficiency was further verified by the laboratory experiments as suggested optimum conditions of process variables. 
The three replicate experiments yielded an average maximum $\mathrm{PO}_{4}{ }^{3-}$ removal efficiency of $151.10 \mathrm{mg} \mathrm{g}^{-1}$ ). The good agreement between experimental and predicted results verified the validity of model and the existence of an optimal point. This indicates that RSM is an important technique for the optimization of process variables and for determining the exact optimum values.

\section{Conclusions}

A Box-Behnken experimental design was used to investigate the influence of key factor such as temperature, solution $\mathrm{pH}$, and $\mathrm{AC} / \mathrm{NZVI}$ dose on aqueous $\mathrm{PO}_{4}{ }^{3-}$ removal by AC/NZVI with the response surface methodology. ANOVA results showed a high value of coefficient of determination $\left(R^{2}=0.985\right)$, indicating the satisfactory fitting of the developed quadratic model second-order polynomial regression model with the experimental data. Process optimization was carried out under the optimal conditions of selected variables of removal process; the maximum $\mathrm{PO}_{4}{ }^{3-}$ removal capacity of AC/NZVI was found to be $151.10 \mathrm{mg} \mathrm{g}^{-1}$, which is very close to the experimentally determined value $\left(152.12 \mathrm{mg} \mathrm{g}^{-1}\right)$ and $>8.0 \%$ which is higher than un-optimized removal capacity $\left(140.58 \mathrm{mg} \mathrm{g}^{-1}\right)$. It is concluded that the presence of $\mathrm{AC}$ as a supporting agent with NZVI prevented agglomeration of the resulting NZVI and thus maintained the high surface area and potential reactivity of the nanoparticles. The $\mathrm{pH}$ of the test solution produced the largest effect on $\mathrm{PO}_{4}{ }^{3-}$ removal process in aqueous medium by AC/NZVI and can be used for removal of $\mathrm{PO}_{4}{ }^{3-}$ from water under optimized conditions.

Acknowledgements This work is supported by the Science and Engineering research board (SERB) and Council of Scientific and Industrial Research (CSIR) Government of India.

Open Access This article is distributed under the terms of the Creative Commons Attribution 4.0 International License (http://creativeco mmons.org/licenses/by/4.0/), which permits unrestricted use, distribution, and reproduction in any medium, provided you give appropriate credit to the original author(s) and the source, provide a link to the Creative Commons license, and indicate if changes were made.

\section{References}

Almeelbi T, Bezbaruah A (2012) Aqueous phosphate removal using nanoscale zero-valent iron. J Nanoparticle Res 14:1

Boparai HK, Joseph M, O'Carroll DM (2011) Kinetics and thermodynamics of cadmium ion removal by adsorption onto nano zerovalent iron particles. J Hazard Mater 186:458-465

Du Q, Zhang S, Pan B, Lv L, Zhang W, Zhang Q (2014) Effect of spatial distribution and aging of ZVI on the reactivity of resin-ZVI composites for arsenite removal. J Mater Sci 49:7073-7079
Liu Y, Lowry GV (2006) Effect of particle age ( $\mathrm{Fe}^{0}$ content) and solution $\mathrm{pH}$ on NZVI reactivity: $\mathrm{H}_{2}$ evolution and TCE dechlorination. Environ Sci Technol 40:6085-6090

Lv X, Xu J, Jiang G, Tang J, Xu X (2012) Highly active nanoscale zero-valent iron (nZVI) $-\mathrm{Fe}_{3} \mathrm{O}_{4}$ nanocomposites for the removal of chromium (VI) from aqueous solutions. J Colloid Interface Sci 369:460-469

Meng H, Hu X, Neville A (2007) A systematic erosion-corrosion study of two stainless steels in marine conditions via experimental design. Wear 263:355-362

Mestre AS, Pires J, Nogueira JMF, Carvalho AP (2007) Activated carbons for the adsorption of ibuprofen. Carbon 45:1979-1988

Shao-Feng N, Yong L, Xin-Hua X, Zhang-Hua L (2005) Removal of hexavalent chromium from aqueous solution by iron nanoparticles. J Zhejiang Univ Sci 10:1022-1027

Singh AK, Singh KP (2016) Evaluation of phosphate removal capacity of $\mathrm{Fe}_{3} \mathrm{O}_{4}$-ZVINPs from aqueous solution: optimization using response surface analysis. Res Chem Intermed 42:7397-7415

Singh KP, Gupta S, Singh AK, Sinha S (2010) Experimental design and response surface modeling for optimization of Rhodamine $\mathrm{B}$ removal from water by magnetic nanocomposite. Chem Eng J 165:151-160

Singh KP, Singh AK, Gupta S, Sinha S (2011) Optimization of Cr (VI) reduction by zero-valent bimetallic nanoparticles using the response surface modeling approach. Desalination 270:275-284

Singh KP, Singh AK, Gupta S (2012a) Optimization of nitrate reduction by EDTA catalyzed zero-valent bimetallic nanoparticles in aqueous medium. Environ Sci Pollut Res 19:3914-3924

Singh KP, Singh AK, Singh UV, Verma P (2012b) Optimizing removal of ibuprofen from water by magnetic nanocomposite using BoxBehnken design. Environ Sci Pollut Res 19:724-738

Sleiman N, Deluchat V, Wazne M, Mallet M, Courtin-Nomade A, Kazpard V, Baudu M (2016) Phosphate removal from aqueous solution using ZVI/sand bed reactor: behavior and mechanism. Water Res 99:56-65

Wang Z, Nie E, Li J, Yang M, Zhao Y, Luo X, Zheng Z (2011) Equilibrium and kinetics of adsorption of phosphate onto iron-doped activated carbon. Environ Sci Pollut Res 19:2908-2917

Wang Z, Nie E, Li J, Yang M, Zhao Y, Luo X, Zheng Z (2012) Equilibrium and kinetics of adsorption of phosphate onto iron-doped activated carbon. Environ Sci Pollut Res 19:2908

Xu J, Tan L, Baig SA, Wu D, Lv X, Xu X (2013) Dechlorination of 2, 4-dichlorophenol by nanoscale magnetic Pd/Fe particles: effects of $\mathrm{pH}$, temperature, common dissolved ions and humic acid. Chem Eng J 231:26-35

Yetilmezsoy K, Saral A (2007) Stochastic modeling approaches based on neural network and linear-nonlinear regression techniques for the determination of single droplet collection efficiency of countercurrent spray towers. Environ Model Assess 12:13-26

You X, Farran A, Guaya D, Valderrama C, Soldatov V, Cortina JL (2016) Phosphate removal from aqueous solutions using a hybrid fibrous exchanger containing hydrated ferric oxide nanoparticles. J Environ Chem Eng 4:388-397

Zhang G, Liu H, Liu R, Qu J (2009) Removal of phosphate from water by a $\mathrm{Fe}-\mathrm{Mn}$ binary oxide adsorbent. J Colloid Interface Sci 335:168-174

Zhang C, Li Y, Wang F, Yu Z, Wei J, Yang Z, Ma C, Li Z, Xu ZY, Zeng G (2017) Performance of magnetic zirconium-iron oxide nanoparticle in the removal of phosphate from aqueous solution. Appl Surf Sci 396:1783-1792

Zhu H, Jia Y, Wu X, Wang H (2009) Removal of arsenic from water by supported nano zero-valent iron on activated carbon. J Hazard Mater 172:1591-1596 